\title{
ДИФФУЗНОЕ ЗАГРЯЗНЕНИЕ ПОВЕРХНОСТНЫХ ВОДНЫХ ОБЪЕКТОВ СОЛИКАМСКО-БЕРЕЗНИКОВСКОГО ПРОМУЗЛА: МАСШТАБЫ, ГЕНЕЗИС
}

\author{
А.П. ЛЕПИХИН ${ }^{1}$, А.В. БОГОМОЛОВ ${ }^{1}$, А.А. ВОЗНЯК ${ }^{1}$, \\ Т.П. ЛЮБИМОВА ${ }^{2}$, Я.Н. ПАРШАКОВА ${ }^{2}$ \\ ${ }^{1}$ Горный институт УрО РАН, г. Пермь \\ ${ }^{2}$ Институт механики сплошных сред УрО РАН, г. Пермь
}

\begin{abstract}
Аннотация: Результативность планирования водоохранных мероприятий, оценка эффективности их реализации требуют полноценной информации о масштабах и характере техногенных воздействий на водные объекты. В настоящее время количественный и качественный состав отводимых сточных вод декларируется водопользователями в материалах официальной отчетности по форме 2ТП-водхоз. В этой форме отчетности отражается информация, как правило, только о сосредоточенных, точечных источниках загрязнения. Однако в зонах активного техногенного воздействия, наряду с данными точечными источниками загрязнения, существенную роль могут играть не точечные, рассредоточенные источники загрязнения, характеризующиеся диффузным механизмом поступления поллютантов в водные объекты. При этом, как правило, все не декларируемые источники рассматриваются как диффузные.

В настоящей статье рассматриваются масштабы и особенности формирования данного источника загрязнения р. Камы (Камского водохранилища) в пределах Соликамско-Березниковского промузла. Эта промышленная агломерация, основанная в значительной мере на разработке одного из крупнейших в мире месторождения калийных и магниевых солей, является наиболее крупным техногенным источником загрязнения р. Камы.
\end{abstract}

Ключевые слова: водные объекты, диффузное загрязнение, оценки, Камское водохранилище.

В настоящее время основными водопользователями рассматриваемой промышленной агломерации являются предприятия гг. Соликамска и Березников, активно использующие в своих технологических цепочках сырье, получаемое в результате разработки Верхнекамского месторождения калийных и магниевых солей (далее ВКМКМС). Избыточные рассолы, формируемые на этих предприятиях, характеризуются очень высокой хлоридно-натриевой, хлоридно-калиевой и магниевокальциевой минерализацией. Такими являются не только предприятия калийной промышленности, но и содовой, и магниевой промышленности, составляющие костяк индустриального комплекса Соликамско-Березниковского промузла. Общая оценка масштабов техногенных воздействий данного комплекса на р. Каму дается в [1].

Для объективной оценки гидрохимического режима р. Камы, наряду с материалами сетевых наблюдений Пермского ЦГМС, использовались материалы ведомственного мониторинга в пределах Соликамско-Березниковского промузла (в первую очередь данные ООО «Промканал»).

Согласно материалам гидрохимических наблюдений, естественные воды р. Камы (Камского водохранилища) представляют собой слабо минерализованную (80-140 мг/л) воду гидрокарбонатного класса. Хлоридов, сульфатов очень мало (0,05 ПДК). В то же время она характеризуется повышенным содержанием железа 8-16 ПДК, 2-3 ПДК по меди, 1-2 ПДК по цинку, 13-16 ПДК по марганцу. Высокое содержание данных ингредиентов характерно и для других рек Урала и их следует рассматривать как естественные региональные особенности [2].

Интегральная оценка диффузной составляющей техногенного загрязнения, поступающего на рассматриваемом участке в р. Каму (Камское водохранилище), проводилась на основе прямой балансовой схемы. При этом для оценки потоков веществ в самом водотоке-приемнике использовались два совершенно независимых 
массива данных: материалы сетевых наблюдений Пермского ЦГМС за период с 1994 по 2015 гг., а также материалы детальных полевых исследований, выполненных в июнеавгусте 2018 г. Характерной особенностью материалов сетевых наблюдений является то, что при их проведении отбор проб производится только на одной вертикали в створе и на двух горизонтах: поверхность, дно. При проведении полевых работ измерения проводились по детализированной схеме: в створе от 3 до 12 вертикалей, сечение измерительных горизонтов назначались через 1 м. Расчет массы ЗВ проводился с использованием поля концентраций, определение расхода воды - с использованием поля скоростей и профиля русла.

Как показали проведенные расчеты, оценки потоков загрязняющих веществ по двум независимым массивам данных дали весьма близкие результаты. Общий суммарный привнос минеральных веществ на рассматриваемом участке р. Камы между постами пгт Тюлькино - г. Орел составил 175-185 кг/с или 460-480 тыс. т. в месяц. Данное обстоятельство достаточно хорошо объясняется тем, что к контрольному створу (для г. Березника это г. Орел) вследствие особенностей морфометрии р. Камы на данном участке распределение макрокомпонентов по поперечному сечению значительно выравнивается и их оценки по двухточечной схеме ЦГМС достаточно объективно отражают их потоки. Небольшие расхождения объясняются разными периодами, за которые были взяты данные для расчета.

В табл. 1 представлены доли загрязняющих веществ по отдельным, декларируемым и не декларируемым, источникам загрязнения. Результаты расчетов, представленные в табл. 1, показывают, что масса ЗВ в результате диффузного загрязнения на участке Камского водохранилища в районе Соликамско-Березниковского промузла значительно (в среднем, в 8 раз) больше декларируемого сброса загрязняющих веществ. В целом, согласно выполненным оценкам, общая масса минеральных загрязняющих веществ, поступающих на рассматриваемом участке в Камское водохранилище в районе Соликамско-Березниковского промузла вследствие не декларируемого диффузного приноса, составляет 5,8 млн тонн в год при средней интенсивности 180 кг/с. При этом 89\% этой диффузной составлявшей приходится на участок Камского водохранилища, прилегающего к г. Березники.

Таблица 1

Доли загрязняющих веществ (\%), поступающие в р. Каму (Камское водохранилище) от разных источников в пределах Соликамско-Березниковского промузла

\begin{tabular}{|l|c|c|c|c|c|c|}
\hline \multicolumn{1}{|c|}{ Источник } & Магний & Хлориды & Сульфаты & Минерализация & Калий & Натрий \\
\hline $\begin{array}{l}\text { \% привноса от } \\
\text { декларируемых } \\
\text { источников }\end{array}$ & 6,4 & 4,9 & 5,9 & 5,6 & 34,4 & 18,8 \\
\hline $\begin{array}{l}\text { \% привноса от } \\
\text { диффузных источников }\end{array}$ & 93,6 & 95,1 & 94,1 & 94,4 & 65,6 & 81,2 \\
\hline $\begin{array}{l}\text { Отношение диффузного } \\
\text { стока к декларируемому } \\
\text { сбросу }\end{array}$ & 14,7 & 19,2 & 15,9 & 16,8 & 1,9 & 4,3 \\
\hline
\end{tabular}

Проведенные в мае и августе 2018 г. детальные полевые исследования распределения минерализации в р. Кама в районе Соликамско-Березниковского промузла показали, что основными источниками диффузного загрязнения являются фильтрационные разгрузки из шламохранилища «Белое море», расположенного в г. Березники, непосредственно прилегающего к р. Кама (рис. 1-2). При этом данные фильтрационные разгрузки поступают в водохранилище в самый нижний придонный слой. Вследствие повышенной плотности фильтрующих рассолов они весьма устойчивы к вертикальному перемешиванию и, как 
результат, на данном участке водохранилища минерализация воды в придонных горизонтах более чем на порядок превышает их содержание в поверхностных слоях.

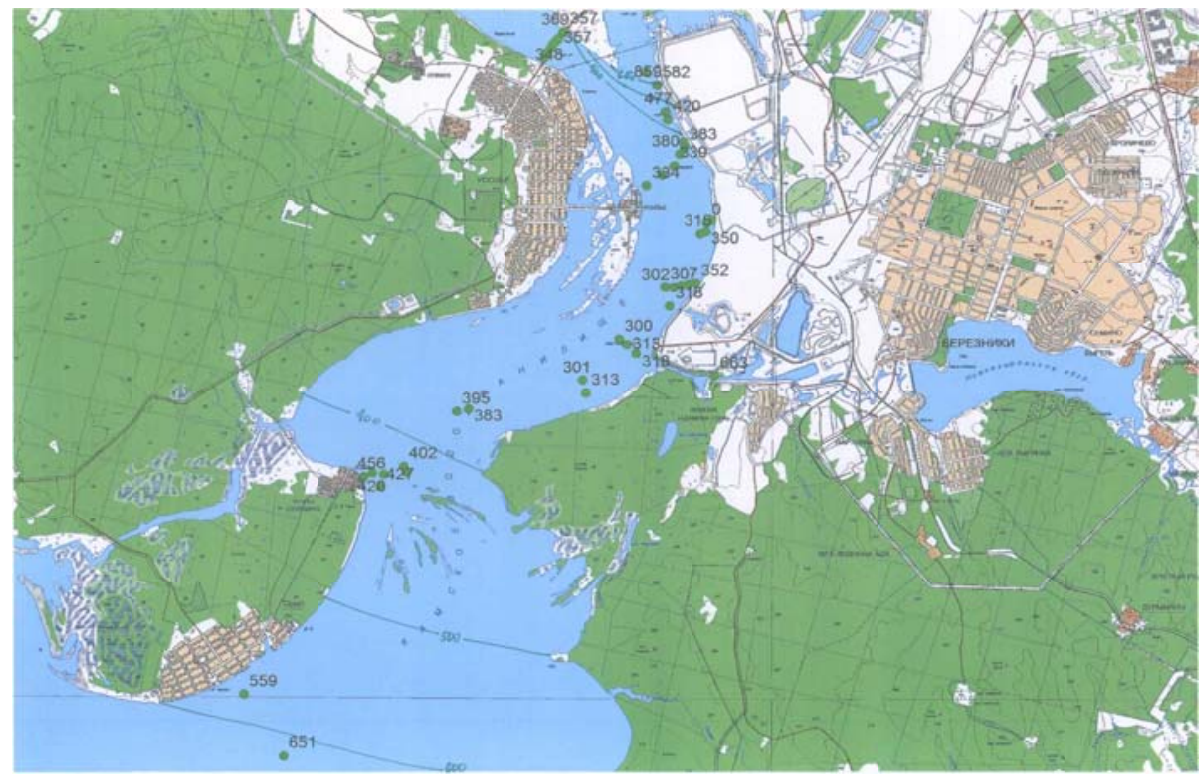

Рис. 1. Карта-схема распределения удельной электропроводности для периода летней межени в поверхностном слое (Березники)

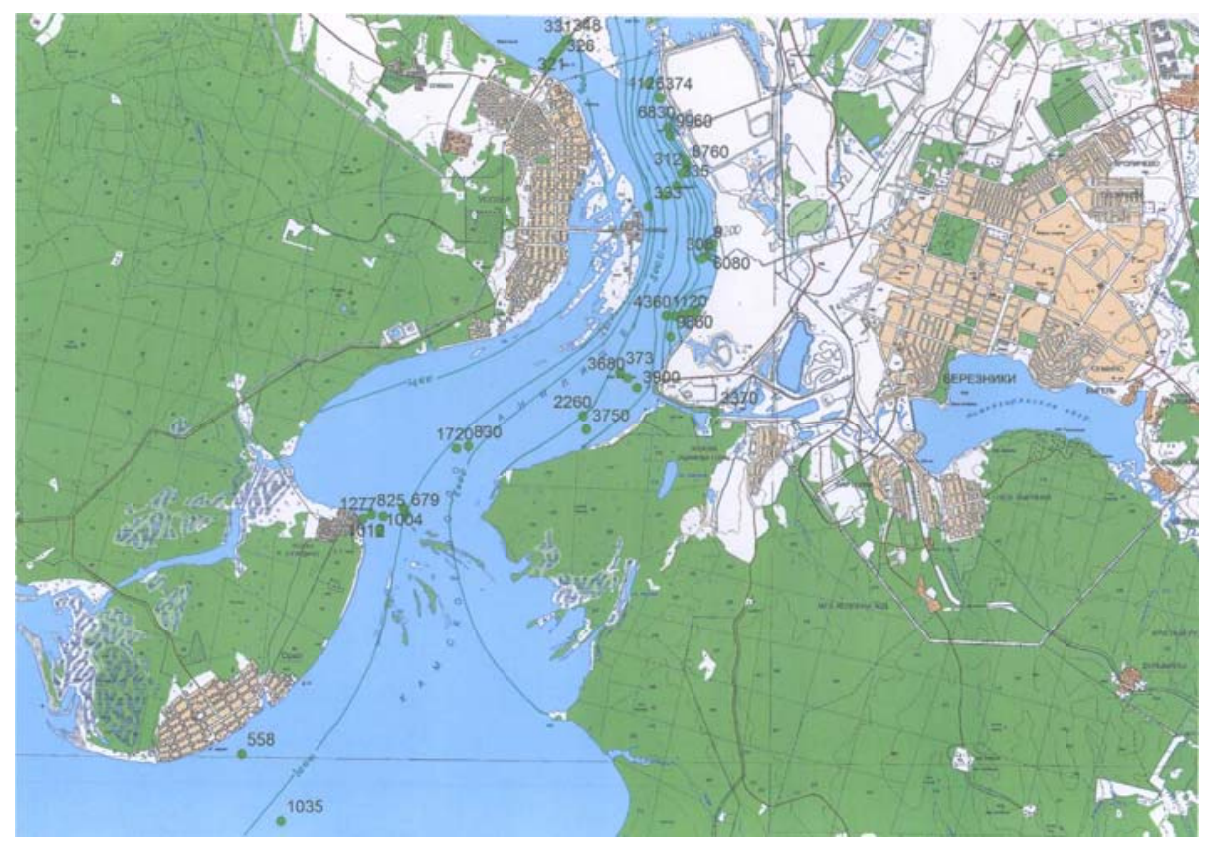

Рис. 2. Карта-схема распределения удельной электропроводности для периода летней межени в придонной области (Березники)

Для того чтобы получить дополнительную информацию о характере источника диффузного загрязнения, с одной стороны, и оценить особенности формирования зон загрязнения от данного источника загрязнения, характеризующегося высокой плотностью фильтрующихся рассолов, с другой, была поставлена задача - построить наблюдаемые поля загрязнений на основе гидродинамических моделей. Расположение принятой расчетной области представлено на рис. 3. В качестве источника загрязнения рассматривались 
фильтрационные разгрузки из шламохранилища «Белое море». Трехмерное численное моделирование проводилось с помощью пакета прикладных программ ANSYS Fluent, основанного на реализации метода конечных объемов. Данный программный продукт позволяет весьма эффективно проводить гидродинамические расчеты в стратифицированных средах в не гидростатическом приближении. Программа весьма успешно использовалась нами для расчета как полей минерализации [3], так и температурных полей [4].

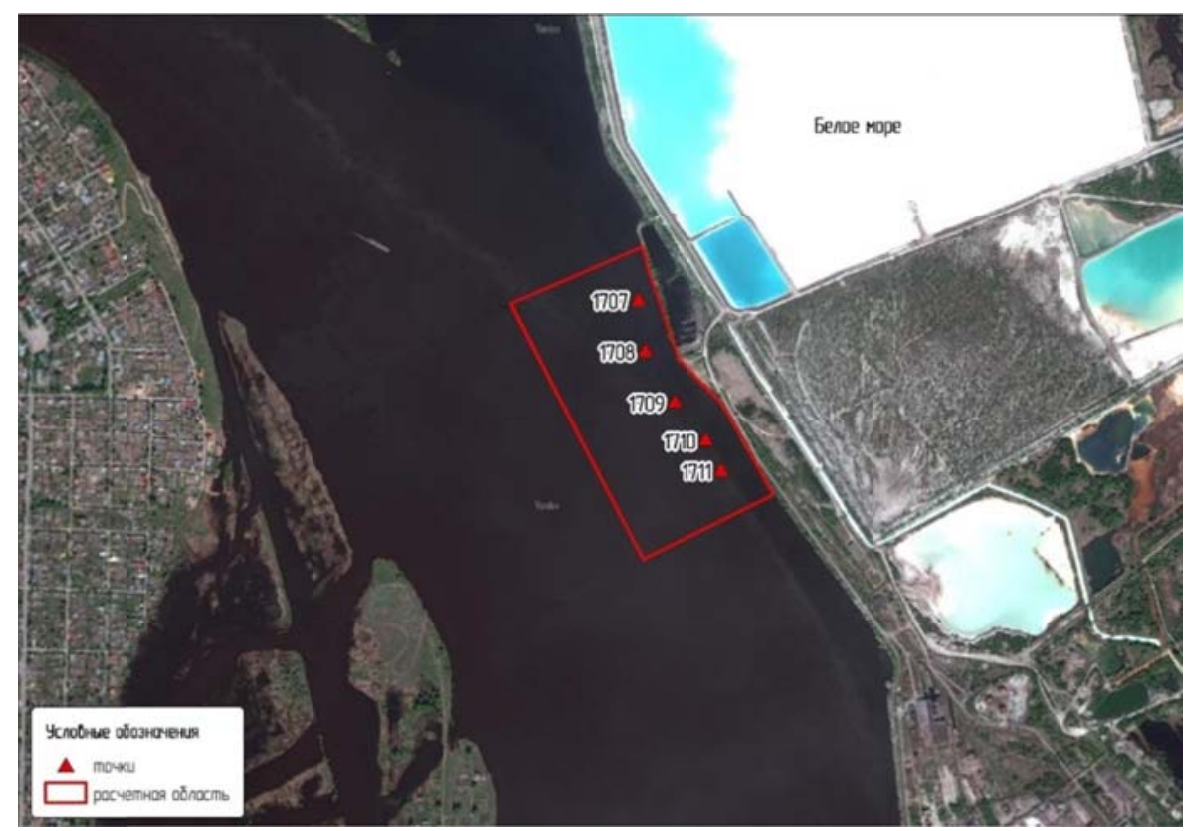

Рис. 3. Расположение и геометрия расчетной области

Результаты расчетов представлены на рис. 4.

Как следует из рис. 4, используемая гидродинамическая модель позволяет достаточно объективно воспроизводить не только качественные особенности вертикальной структуры полей минерализации, но и численные параметры. Наиболее яркой их особенностью является, как уже отмечалось, очень значительная вертикальная неоднородность. Данная особенность имеет принципиальное значение при организации отведения высокоминерализованных рассолов в водные объекты. Для того чтобы не допускать подобной вертикальной неоднородности, необходимо обеспечение их эффективного начального разбавления [5].
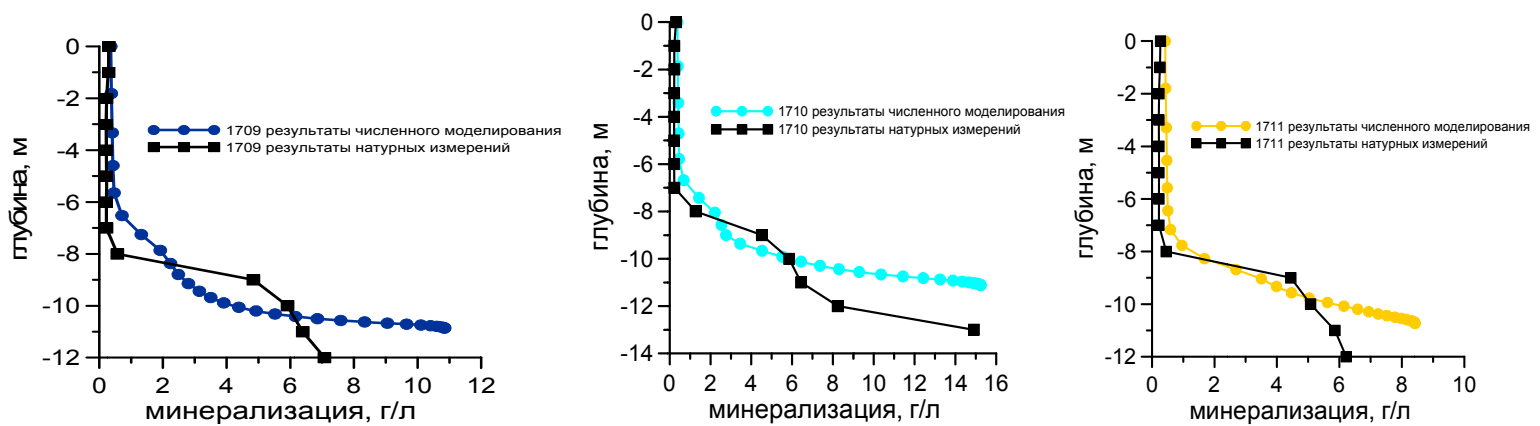

Рис. 4. Распределение минерализации по глубине согласно данным численных расчетов и натурных измерений для вертикали 1709, 1710, 1711

Выполненная оценка интенсивности потоков поллютантов, поступающих на данном участке р. Камы (Камского водохранилища), показала, что доминирующий вклад 
вносят недекларируемые, рассредоточенные источники загрязнения, связанные с фильтрационными разгрузками из шламохранилища.

В районе г. Березники фильтрационные разгрузки из шламохранилища, расположенного в северной части города непосредственно на левом берегу p. Камы (Камского водохранилища), формируют в придонной области очень существенную зону загрязнения. По материалам полевых исследований, выполненных в августе, интенсивность данного источника загрязнения составляет q 157 кг/сек при линейных размерах $\sim 1000$ м.

Разработанная гидродинамическая модель в 3D постановке, в негидростатическом приближении, позволяет достаточно хорошо воспроизводить особенности распределения полей минерализации воды, формируемых вследствие фильтрационных разгрузок из шламохранилища «Белое море».

\title{
БИБЛИОГРАФИЧЕСКИЙ СПИСОК
}

1. Лепихин А.П., Мирошниченко С.А Техногенное воздействие Соликамско-Березниковского промузла на поверхностные водные объекты / А.П. Лепихин, С.А. Мирошнеченко // Горн. журн. - 2008. - № 10. - С. $92-96$.

2. Лепихин А.П., Возняк А.А. Разработка региональных ПДК: необходимость, методика, пример / А.А. Возняк, А.П. Лепихин // Географич. вестн. - 2018. - № 2 (45). - С. 103-115. DOI:10.17072/2079-78772018-2-103-115.

3. Lyubimova T. ,Lepikhin A. Parshakova Yu., Lyakhin Y. Tiunov A. The modeling of the formation of technogenic thermal pollution zones in large reservoirs // International journal of Heat and Mass Transfer. 2018. - V. 126. - November. - P. 342-352. DOI: 10.1016/j.ijheatmasstransfer.2018.05.017.

4. Любимова Т.П., Лепихин А.П., Паршакова Я.Н., Тиунов А.А Численное моделирование разбавления и переноса высокоминерализованных рассолов в турбулентных потоках // Вычислительная механика сплошных сред. - 2010. - № 4. - С. 68-79.

5. Лепихин А.П., Богомолов А.В. Особенности отведения избыточных рассолов предприятий калийной промышленности в поверхностные водные объекты // Горн. журн. - 2018. - № 6. - С. 21-24. DOI: 10.17580/gzh.2018.06.04.

\section{АНАЛИЗ ГИДРОДИНАМИЧЕСКОЙ СИТУАЦИИ НА р. КАМА, ОБУСЛОВИВШЕЙ ВЫНОС СУДОВ В Г. ПЕРМИ С МЕСТ ИХ ЗИМНЕГО ОТСТОЯ}

\author{
А.А. ТИУНОВ \\ Горный институт УрО РАН, г. Пермь
}

\begin{abstract}
Аннотация: Аварийные ситуации на водных объектах, как правило, связаны с резкими изменениями гидродинамических характеристик на данном водном объекте и с человеческим фактором. Так 22 января 2019 года в г. Перми произошла серьезная аварийная ситуация, в результате которой несколько судов, находившихся в зимнем отстое в районе порта Кама г. Пермь, были сорваны с мест стоянки и вынесены на фарватер р. Кама. В ходе проведенного гидродинамического моделирования было показано, что аварийная ситуация была обусловлена совокупностью факторов: резкое изменение гидрологического режима р. Кама в данном районе и погодных условий, сильные морозы и, как следствие, образование большого количества льда в районе отстоя судов.
\end{abstract}

Ключевые слова: гидродинамическая модель, гидрологический режим, аварийная ситуация на р. Кама.

Серьезные аварийные ситуации на водных объектах, как правило, обусловливаются значительными изменениями их гидрологического режима.

Двадцать второго января 2019 года в г. Перми произошла серьезная аварийная ситуация, в результате которой несколько судов, находившихся в зимнем отстое в районе порта Кама г. Пермь (рисунок 1), были сорваны с мест стоянки и вынесены на фарватер 